PACS 36.10.-k

Dubrovskaya Yu. V., Khetselius O. Yu., Serga I. N., Chernyakova Yu. G.

Odesa State Environmental University, L’vovskaya str., 15, Odesa, 65016, Ukraine

E-mail: dubrovskayayv@gmail.com

\title{
RELATIVISTIC THEORY OF SPECTRAL CHARACTERISTICS OF PIONIC ATOMIC SYSTEMS: APPLICATION TO HEAVY SYSTEMS
}

\begin{abstract}
A new theoretical approach to energy and spectral parameters of the hadronic (pionic and kaonic) atoms in the excited states with precise accounting for the relativistic, radiation and nuclear effects is presented. There are presented data of calculation of the energy and spectral parameters for pionic atoms of the ${ }^{93} \mathrm{Nb},{ }^{173} \mathrm{Yb},{ }^{181} \mathrm{Ta}$, 197

$\mathrm{Au}$, with accounting for the radiation (vacuum polarization), nuclear (finite size of a nucleus ) and the strong pion-nuclear interaction corrections. The measured values of the Berkley, CERN and Virginia laboratories and alternative data based on other versions of the Klein-Gordon-Fock theories with taking into account for a finite size of the nucleus in the model uniformly charged sphere and the standard Uhling-Serber potential approach for account for the radiation corrections are listed too.
\end{abstract}

\section{Introduction}

Our work is devoted to the further application of earlier developed new theoretical approach [1-8] to the description of spectra and different spectral parameters, in particular, radiative transitions probabilities for hadronic (pionic and kaonic) atoms in the excited states with precise accounting for the relativistic, nuclear and radiative effects. It is well known that studying the energy, spectral, radiation parameters, including the spectral lines hyperfine structure, for heavy exotic (hadronic, kaonic, pionic) atomic systems is of a great interest for the further development as atomic and nuclear theories and quantum chemistry of strongly interacted fermionic systems (see, for example, refs. [1-45]). Really, the exotic atoms enable to probe aspects of atomic and nuclear structure that are quantitatively different from what can be studied in the electronic ("usual") atoms. Besides, the corresponding data on the energy and spectral properties of the hadronic atomic systems can be used as a powerful tool for the study of particles and fundamental properties.

While determining the properties of pion atoms in theory is very simple as a series of $\mathrm{H}$ such models and more sophisticated methods such combination chiral perturbation theory (TC), adequate quantitative description of the spectral properties of atoms in the electromagnetic pion sector (not to mention even the strong interaction sector ) requires the development of High-precision approaches, which allow you to accurately describe the role of relativistic, nuclear, radiation QED (primarily polarization electronpositron vacuum, etc.). pion effects in the spectroscopy of atoms.

The most popular theoretical models for pionic and kaonic atoms are naturally based on the using the Klein-Gordon-Fock equation, but there are many important problems connected with accurate accounting for as pion-kaon-nuclear strong interaction effects as QED radiative corrections (firstly, the vacuum polarization effect etc.). This topic has been a subject of intensive theoretical and experimental interest (see [1-16]). The perturbation theory expansion on the physical; parameter $\alpha Z$ is usually used to take into account the radiative QED corrections, first of all, effect of the polarization of electronpositron vacuum etc. This approximation is sufficiently correct and comprehensive in a case of the light pionic atoms, however it becomes incorrect in a case of the heavy atoms with large charge of a nucleus $\mathrm{Z}$.

The more correct accounting of the QED, finite nuclear size and electron-screening effects for pionic atoms is also very serious and actual problem to be solved more consistent- 
ly in comparison with available theoretical models and schemes.

In this paper we present an effective theoretical approach to computing energy and spectral parameters of the hadronic (pionicc) atoms in the excited states with precise accounting for the relativistic, radiation and nuclear effects. There are presented data of calculation of the energy and spectral parameters for pionic atoms of the ${ }^{93} \mathrm{Nb},{ }^{173} \mathrm{Yb}$, ${ }^{181} \mathrm{Ta},{ }^{197} \mathrm{Au}$, with accounting for the radiation (vacuum polarization), nuclear (finite size of a nucleus ) and the strong pionnuclear interaction corrections. The measured values of the Berkley, CERN and Virginia laboratories and alternative data based on other versions of the Klein-Gordon-Fock theories with taking into account for a finite size of the nucleus in the model uniformly charged sphere and the standard UhlingSerber potential approach for account for the radiation corrections are listed too.

\section{Theory}

The basic topics of our theoretical approach have been earlier presented [3$8,27,28]$, so here we are limited only by the key elements. The relativistic dynamic of a spinless boson (pion) particle is described by the Klein-Gordon-Fock (KGF) equation. As usually, an electromagnetic interaction between a negatively charged pion and the atomic nucleus can be taken into account introducing the nuclear potential $\mathrm{A}_{v}$ in the $\mathrm{KG}$ equation via the minimal coupling $\mathrm{p}_{v} \rightarrow \mathrm{p}_{v}{ }^{-}$ $\mathrm{qA}_{v}$. Generally speaking, the Klein-GordonFock equation can be rewritten as the corresponding two-component equation :

$$
\left[-\left(\sigma_{3}+i \sigma_{2}\right) \frac{\nabla^{2}}{2 \mu}+\sigma_{3} \mu+\left(\sigma_{3}+i \sigma_{2}\right) V_{o p t}^{(0)}+V_{C}^{(0)}\right] \Psi_{i}=E_{i} \Psi_{i}
$$

where $\sigma_{i}$ are the Pauli spin matrices and

$$
\Psi_{i}=\frac{1}{2}\left(\begin{array}{c}
\left(1+\left(E-V_{C}^{(0)}\right) / \mu\right) \phi_{i} \\
\left(1-\left(E-V_{C}^{(0)}\right) / \mu\right) \phi_{i}
\end{array}\right)
$$

This equation is equivalent to the stationary Klein-Gordon-Fock equation. The corre- sponding non-stationary Klein-Gordon-Fock equation can be written as follows:

$$
\mu^{2} c^{2} \Psi(x)=\left\{\frac{1}{c^{2}}\left[i \hbar \partial_{t}+e V_{0}(r)\right]^{2}+\hbar^{2} \nabla^{2}\right\} \Psi(x)
$$

where $\mathrm{c}$ is the speed of light, $h$ is the Planck constant, $\mu$ is the reduced mass of the pionnuclear system, and $\Psi_{0}(\mathrm{x})$ is the scalar wave function of the space-temporal coordinates. Usually one considers the central potential $\left[\mathrm{V}_{0}(\mathrm{r}), 0\right]$ approximation with the stationary solution:

$$
\Psi(\mathrm{x})=\exp (-\mathrm{iE} t / \hbar) \phi(x)
$$

where $\phi(x)$ is the solution of the equation:

$$
\left\{\frac{1}{c^{2}}\left[E+e V_{0}(r)\right]^{2}+\hbar^{2} \nabla^{2}-\mu^{2} c^{2}\right\} \phi(x)=0
$$

Here $E$ is the total energy of the system (sum of the mass energy $\mathrm{mc}^{2}$ and binding energy $\left.\varepsilon_{0}\right)$. In principle, the central potential $V_{0}$ is the sum of the following potentials: the electric potential of a nucleus, vacuum-polarization potential.

The strong interaction potential can be added below. Generally speaking, an energy of the pionic atomic system can be represented as the following sum:

$$
E \approx E_{K G}+E_{F S}+E_{Q E D}+E_{N},
$$

where $E_{K G}$ is the energy of a pion in a nucleus $(Z, A)$ with the point-like charge, $E_{F S}$ is the contribution due to the nucleus finite size effect, $E_{V P}$ is the radiation QED correction, $E_{N}$ is the energy shift due to the strong (pionor kaon- nuclear) interaction $V_{N}$.

In principle, the central potential $V_{0}$ should include the central Coulomb potential, the radiative (in particular, vacuumpolarization) potential as well as the electronscreening potential in the atomic-optical (electromagnetic) sector. Surely, the full solution of the pionic atom energy especially 
for the low-excited state requires an inclusion the hadron-nuclear strong potential.

The next step is accounting the nuclear finite size effect or the Breit-RosenthalCrawford-Schawlow one. In order to do it we use the widespread Gaussian model for nuclear charge distribution. The advantages of this model in comparison with usually used models such as for example an uniformly charged sphere model and others had been analysed in Ref. [3]. Usually the Gauss model is determined as follows:

$$
\rho(r \mid R)=\left(4 \gamma^{3 / 2} / \sqrt{\pi}\right) \exp \left(-r^{2}\right)
$$

where $\gamma=4 \pi / R^{2}$, $\mathrm{R}$ is an effective radius of a nucleus.

In order to take into account very important radiation QED effects we use the radiative potential from the Flambaum-Ginges theory [15]. In includes the standard UelingSerber potential and electric and magnetic form-factors plus potentials for accounting of the high order QED corrections such as:

$$
\begin{gathered}
\Phi_{r a d}(r)=\Phi_{U}(r)+\Phi_{g}(r)+\Phi_{f}(r)+. \\
+\Phi_{l}(r)+\frac{2}{3} \Phi_{U}^{\text {high-order }}(r)
\end{gathered}
$$

where

$$
\begin{gathered}
\Phi_{U}^{\text {high-order }}(r)=-\frac{2 \alpha}{3 \pi} \Phi(r) \frac{0.092 Z^{2} \alpha^{2}}{1+\left(1.62 r / r_{C}\right)^{4}} . \\
\Phi_{l}(r)=-\frac{B(Z)}{e} Z^{4} \alpha^{5} m c^{2} e^{-Z r / a_{B}}
\end{gathered}
$$

Here $e-$ a proton charge and universal function $B(Z)$ is defined by expression: $B(Z)=0.074+0.35 Z \alpha$.

At last to take into account the electron screening effect we use the standard procedure, based on addition of the total interac- tion potential SCF potential of the electrons, which can be determined within the DiracFock method by solution of the standard relativistic Dirac equations. It should be noted however, that contribution of theses corrections is practically zeroth for the pionic nitrogen, however it can be very important in transition to many-electron as a rule heavy hadronic atoms.

Further in order to calculate probabilities of the radiative transitions between energy level of the pionic atoms we have used the well-known relativistic energy approach (c. g.[16-28]). Other details are in Refs. [4,7,8].

\section{Results and conclusions}

In Table 1 the numerical data on the $4 f$ $3 d, 5 g-4 f$ transition energies for pionic atoms of the ${ }^{93} \mathrm{Nb},{ }^{173} \mathrm{Yb},{ }^{181} \mathrm{Ta},{ }^{197} \mathrm{Au}$ are presented. There are also listed the measured values of the Berkley, CERN and Virginia laboratories and alternative data obtained on the basis of computing within alternative versions of the Klein-Gordon-Fock (KGF) theory with taking into account for a finite size of the nucleus in the model uniformly charged sphere and the standard Uehling-Serber radiation correction (see Refs. [5, 6,7,13]).

The analysis of the presented data indicate on the importance of the correct accounting for the radiation (vacuum polarization) and the strong pion-nuclear interaction corrections. The contributions due to the nuclear finite size effect should be accounted in a precise theory too.

More exact knowledge of the electromagnetic interaction parameters for a pionic atom will make more clear the true values for parameters of the pion-nuclear potentials. Further it allows to correct a disadvantage of widely used parameterization of the optical potential. It is especially important if one takes into account an increasing accuracy of the X-ray pionic atom spectroscopy experiments.

Table 1.

Transition energies $(\mathrm{keV})$ in the spectra of some heavy pionic atoms (see text) 


\begin{tabular}{|c|c|c|c|c|}
\hline$\pi-\mathrm{A}$ & Trans. & $\begin{array}{c}\text { Berkley } \\
\mathrm{E}_{\text {EXP }}\end{array}$ & $\begin{array}{c}\text { CERN } \\
\mathrm{E}_{\text {EXP }}\end{array}$ & $\begin{array}{c}\mathrm{E}_{\mathrm{KGF}+\mathrm{EM}} \\
{[6,7]}\end{array}$ \\
\hline${ }^{93} \mathrm{Nb}$ & $5 \mathrm{~g}-4 \mathrm{f}$ & - & $307.79 \pm 0.02$ & - \\
\hline${ }^{173} \mathrm{Yb}$ & $5 \mathrm{~g}-4 \mathrm{f}$ & - & - & - \\
\hline${ }^{181} \mathrm{Ta}$ & $5 \mathrm{~g}-4 \mathrm{f}$ & $453.1 \pm 0.4$ & $453.90 \pm 0.20$ & 453.06 \\
\hline${ }^{197} \mathrm{Au}$ & $5 \mathrm{~g}-4 \mathrm{f}$ & $532.5 \pm 0.5$ & $533.16 \pm 0.20$ & 528.95 \\
\hline${ }^{93} \mathrm{Nb}$ & $4 \mathrm{f}-3 \mathrm{~d}$ & - & $140.3 \pm 0.1$ & - \\
\hline${ }^{173} \mathrm{Yb}$ & $4 \mathrm{f}-3 \mathrm{~d}$ & - & - & - \\
\hline${ }^{181} \mathrm{Ta}$ & $4 \mathrm{f}-3 \mathrm{~d}$ & - & $1008.4 \pm 1.3$ & - \\
\hline${ }^{\pi-\mathrm{A}}$ & Trans. & $\mathrm{E}_{\mathrm{KGF}-\mathrm{EM}}$ & $\mathrm{E}_{\mathrm{N}}$ & Our \\
& & {$[13]$} & {$[13]$} & data \\
\hline${ }^{93 \mathrm{Nb}}$ & $5 \mathrm{~g}-4 \mathrm{f}$ & - & - & 307.85 \\
\hline${ }^{173 \mathrm{Yb}}$ & $5 \mathrm{~g}-4 \mathrm{f}$ & - & - & 412.26 \\
\hline${ }^{181 \mathrm{Ta}}$ & $5 \mathrm{~g}-4 \mathrm{f}$ & 453.78 & 453.52 & 453.71 \\
& & & 453.62 & \\
\hline${ }_{197 \mathrm{Au}}$ & $5 \mathrm{~g}-4 \mathrm{f}$ & - & 531.88 & 533.08 \\
\hline${ }^{93 \mathrm{Nb}}$ & $4 \mathrm{f}-3 \mathrm{~d}$ & - & - & 140.81 \\
\hline${ }^{173 \mathrm{Yb}}$ & $4 \mathrm{f}-3 \mathrm{~d}$ & - & - & 838.67 \\
\hline${ }^{181 \mathrm{Ta}}$ & $4 \mathrm{f}-3 \mathrm{~d}$ & - & 992.75 & 1008.80 \\
\hline
\end{tabular}

It is interesting to note that the contributions into transition energies are about $\sim 5 \mathrm{keV}$ due to the QED effects, $\sim 0,2 \mathrm{keV}$ due to the nuclear finite size effect, and $\sim 0.07 \mathrm{keV}$ due to the electron screening effect, provided by the $2[\mathrm{He}], 4[\mathrm{Be}], 10[\mathrm{Ne}]$ electron shells [5].

\section{References}

1. Khetselius, O.Yu. Relativistic perturbation theory calculation of the hyperfine structure parameters for some heavy-element isotopes. Int. J. Quant. Chem. 2009, 109, 3330-3335.

2. Khetselius, O. Relativistic calculation of the hyperfine structure parameters for heavy elements and laser detection of the heavy isotopes. Phys. Scripta 2009, 135, 014023.

3. Khetselius, O. Hyperfine structure of atomic spectra; Astroprint: Odessa, 2008.

4. Dubrovskaya, Yu., Khetselius, O.Yu., Vitavetskaya, L., Ternovsky, V., Serga, I. Quantum chemistry and spectroscopy of pionic atomic systems with accounting for relativistic, radiative, and strong interaction effects. $A d v$. in Quantum Chem. 2019, 78, 193-222.
5. Khetselius, O.Yu., Glushkov, A.V., Dubrovskaya, Yu.V., Chernyakova, Yu.G., Ignatenko, A.V., Serga, I.N., Vitavetskaya, L. Relativistic quantum chemistry and spectroscopy of exotic atomic systems with accounting for strong interaction effects. In: Wang YA, Thachuk M, Krems R, Maruani J (eds) Concepts, Methods and Applications of Quantum Systems in Chemistry and Physics. Springer, Cham, 2018; Vol. 31, pp. 7191.

6. Serga, I.N.; Dubrovskaya, Yu.V.; Kvasikova, A.S.; Shakhman, A.N; Sukharev, D.E. Spectroscopy of hadronic atoms: Energy shifts. J. Phys.: Conf. Ser. 2012, 397, 012013.

7. Serga, I.N.; Khetselius, O.Yu.; Vitavetskaya, L.A.; Bystryantseva A.N. Relativistic theory of spectra of pionic atomic systems ${ }^{208} \mathrm{~Pb}$ with account of strong pion-nuclear interaction effects. Photoelectronics. 2017, 26, 68-77.

8. Sukharev, D.E.; Khetselius, O.Yu.; Dubrovskaya, Yu.V. Sensing strong interaction effects in spectroscopy of hadronic atoms. Sensor Electr. and $\mathrm{Mi}$ crosyst. Techn. 2009, N3, 16-21.

9. Khetselius, O.Yu. Quantum structure of electroweak interaction in heavy finite Fermi-systems. Astroprint: Odessa, 2011.

10. Khetselius, O.Y.., Glushkov, A.V., Gurskaya, M.Y., Kuznetsova, A.A., Dubrovskaya, Yu.V., Serga, I.N., Vitavetskaya, L.A. Computational modelling parity nonconservation and electroweak interaction effects in heavy atomic systems within the nuclear-relativistic many-body perturbation theory. J. Phys.: Conf. Ser. 2017, 905(1), 012029.

11. Batty, C.; Eckhause, M.; Gall, K. et al. Strong interaction effects in high-Z $\mathrm{K}^{-}$ atoms. Phys. Rev. C. 1989, 40, 2154.

12. Erikcson, M.; Ericson, T. Optical Properties of Low Energy Pions in Nuclei. Ann. Phys. 1966, 36, 323.

13. Batty, C J.; Friedman, E.; Gal, A. Saturation effects in pionic atoms and the $\pi^{--}$ 
nucleus optical potential. Nucl. Phys. A. 1983, 402, 411-428.

14. Indelicato, P. Relativistic effects in fewelectron heavy ions. Ab initio evaluation of levels energy and transitions probabilities. Phys. Scripta 1996, 65, 57.

15. Flambaum, V.; Ginges J. Radiative potential and calculation of QED radiative corrections to energy levels and electromagnetic amplitudes in many-electron atoms. Phys.Rev.A. 2005, 72, 052115.

16. Glushkov A.V., Malinovskaya S.V., Svinarenko A.A., Vitavetskaya L.A., Sensing spectral hierarchy, quantum chaos, chaotic diffusion and dynamical stabilisation effects in a multi- photon atomic dynamics with intense laser field. Sensor Electr. and Microsyst. Techn. 2005, 2(2), 29-35.

17. Mohr, P.J. Quantum Electrodynamics Calculations in few-Electron Systems. Phys. Scripta. 1993, 46, 44.

18. Rusov V., Glushkov A., Vaschenko V., Korchevsky D., Ignatenko A. Stochastic dynamics of the atomic systems in the crossed electric and magnetic field: the rubidium atom recurrence spectra. Bull.of Kiev Nat. Univ.:Ser.Phys.-Math. 2004, N4, 433.

19. Glushkov, A.V. Spectroscopy of cooperative muon-gamma-nuclear processes: Energy and spectral parameters. $J$. Phys.: Conf. Ser. 2012, 397, 012011.

20. Gubanova, E.R., Glushkov, A.V., Khetselius, O.Yu., Bunyakova, Yu., Buyadzhi, V., Pavlenko, E. New methods in analysis and project management of environmental activity: Electronic and radioactive waste. Kharkiv, FOP, 2017.

21. Khetselius, O.Yu., Lopatkin Yu.M., Dubrovskaya, Yu.V, Svinarenko A.A. Sensing hyperfine-structure, electroweak interaction and parity non-conservation effect in heavy atoms and nuclei: New nuclear-QED approach. Sensor Electr. and Microsyst. Techn. 2010, 7(2), 11-19.

22. Bystryantseva A., Khetselius O.Yu., Dubrovskaya Yu., Vitavetskaya L.A., Berestenko A.G. Relativistic theory of spectra of heavy pionic atomic systems with account of strong pion-nuclear interaction effects: ${ }^{93} \mathrm{Nb},{ }^{173} \mathrm{Yb},{ }^{181} \mathrm{Ta}$, ${ }^{197}$ Au. Photoelectronics. 2016,25, 56-61.

23. Glushkov, A.V. Relativistic Quantum theory. Quantum mechanics of atomic systems; Astroprint: Odessa, 2008.

24. Kuznetsova A.A., Vitavetskaya L.A., Chernyakova Yu.G., Korchevsky D., Calculating the radiative vacuum polarization contribution to the energy shift of $2 \mathrm{p}-3 \mathrm{~s}$ transition in pionic deuterium. Photoelectronics. 2013, 22, 108-111.

25. Glushkov, A.V.; Khetselius, O.Yu.; Svinarenko, A.A.; Buyadzhi, V.V. Spectroscopy of autoionization states of heavy atoms and multiply charged ions. Odessa: TEC, 2015.

26. Glushkov, A.V. Spectroscopy of atom and nucleus in a strong laser field: Stark effect and multiphoton Resonances. $J$. Phys.: Conf. Ser. 2014, 548, 012020.

27. Khetselius, O.Yu. Atomic parity nonconservation effect in heavy atoms and observing $\mathrm{P}$ and $\mathrm{PT}$ violation using NMR shift in a laser beam: To precise theory. J. Phys.: Conf. Ser. 2009, 194, 022009.

28. Khetselius, O. Relativistic hyperfine structure spectral lines and atomic parity nonconservation effect in heavy atomic systems within QED theory. AIP Conf. Proc. 2010, 1290, 29-33.

29. Chernyakova, Y.G., Vitavetskaya L., Bashkaryov, P., Serga I., Berestenko, A. The radiative vacuum polarization contribution to the energy shift of some levels of the pionic hydrogen. Photoelectronics 2015, 24, 122-127.

30. Glushkov, A., Gurskaya, M., Ignatenko, A., Smirnov, A., Serga, I., Svinarenko, A., Ternovsky, E. Computational code in atomic and nuclear quantum optics: Advanced computing multiphoton resonance parameters for atoms in a strong laser field. J. Phys.: Conf. Ser. 2017, 905(1), 012004.

31. Ambrosov S., Ignatenko V., Korchevsky D., Kozlovskaya V. Sensing stochasticity of atomic systems in crossed electric and magnetic fields by analysis of level 
statistics for continuous energy spectra. Sensor Electr. and Microsyst. Techn. 2005, Issue 2, 19-23.

32. Glushkov, A.V., Ivanov, L.N. Radiation decay of atomic states: atomic residue polarization and gauge noninvariant contributions. Phys. Lett. A 1992, 170, 33.

33. Glushkov, A.V.; Ivanov, L.N. DC strong-field Stark effect: consistent quantum-mechanical approach. J. Phys. B: At. Mol. Opt. Phys. 1993, 26, L379386.

34. Ivanova, E., Glushkov, A. Theoretical investigation of spectra of multicharged ions of F-like and Ne-like isoelectronic sequences. J. Quant. Spectr. and Rad. Tr. 1986, 36(2), 127-145.

35. Ivanova, E.P., Ivanov, L.N., Glushkov, A., Kramida, A. High order corrections in the relativistic perturbation theory with the model zeroth approximation, Mg-Like and Ne-Like Ions. Phys. Scripta 1985, 32, 513-522.

36. Glushkov, A.V. Relativistic and correlation effects in spectra of atomic systems. Astroprint, Odessa, 2006.

37. Glushkov, A.V. Multiphoton spectroscopy of atoms and nuclei in a laser field: Relativistic energy approach and radiation atomic lines moments method. Adv. in Quantum Chem. 2019, 78, 253-285.

38. Chernyakova, Y.G., Ignatenko A.V., Vitavetskaya L.A., Sensing the tokamak plasma parameters by means high resolution X-ray theoretical spectroscopy method: new scheme. Sensor Electr. and Microsyst. Techn. 2004, 1, 20-24.

39. Glushkov, A.V., Malinovskaya, S.V., Dubrovskaya, Yu.V., Sensing the atomic chemical composition effect on the beta decay probabilities. Sensor Electr. and Microsyst. Techn. 2005, 2(1), 16-20.
40. Glushkov, A.V., Khetselius, O.Yu., Svinarenko, A.A., Buyadzhi, V.V. Methods of computational mathematics and mathematical physics. P.1. Odessa: TES, 2015.

41. Svinarenko, A. A., Glushkov, A. V., Khetselius, O.Yu., Ternovsky,V.B., Dubrovskaya, Yu., Kuznetsova, A., Buyadzhi, V. Theoretical spectroscopy of rare-earth elements: spectra and autoionization resonances. Rare Earth Element, Ed. J. Orjuela (InTech) 2017, pp 83-104

42. Glushkov, A.V., Khetselius, O.Yu., Svinarenko A.A., Buyadzhi, V.V., Ternovsky, V.B, Kuznetsova, A., Bashkarev, P Relativistic perturbation theory formalism to computing spectra and radiation characteristics: application to heavy element. Recent Studies in Perturbation Theory, ed. D. Uzunov (InTech) 2017, 131-150.

43. Danilov, V., Kruglyak, Y., Pechenaya, V. Electron density-bond order matrix and the spin density in the restricted CI method. Theor. Chim Acta. 1969, 13(4), 288-296.

44. Glushkov A.V., Khetselius O.Yu., Loboda A.V., Ignatenko A., Svinarenko A., Korchevsky D., Lovett L., QED Approach to Modeling Spectra of the Multicharged Ions in a Plasma: Oscillator and Electron-ion Collision Strengths.. AIP Conference Proceedings. 2008. 1058. 175-177

45. Glushkov, A.V., Safranov, T.A., Khetselius, O.Yu., Ignatenko, A.V., Buyadzhi, V.V., Svinarenko, A.A. Analysis and forecast of the environmental radioactivity dynamics based on methods of chaos theory: General conceptions. Environm. Problems. 2016, 1(2), 115-120. 
PACS 36.10.-k

Dubrovskaya Yu.V., Khetselius O. Yu., Serga I.N., Chernyakova Yu. G.

\section{RELATIVISTIC THEORY OF SPECTRAL CHARACTERISTICS OF PIONIC ATOMIC SYSTEMS: APPLICATION TO HEAVY SYSTEMS}

Summary. A new theoretical approach to energy and spectral parameters of the hadronic (pionic and kaonic) atoms in the excited states with precise accounting for the relativistic, radiation and nuclear effects is presented. There are presented data of calculation of the energy and spectral parameters for pionic atoms of the ${ }^{93} \mathrm{Nb},{ }^{173} \mathrm{Yb},{ }^{181} \mathrm{Ta},{ }^{197} \mathrm{Au}$, with accounting for the radiation (vacuum polarization), nuclear (finite size of a nucleus ) and the strong pionnuclear interaction corrections. The measured values of the Berkley, CERN and Virginia laboratories and alternative data based on other versions of the Klein-Gordon-Fock theories with taking into account for a finite size of the nucleus in the model uniformly charged sphere and the standard Uhling-Serber potential to account for radiation corrections are listed too.

Keywords: relativistic perturbation theory, energy parameters, pionic atomic systems

PACS 36.10.-k

Дубровская Ю.В., Хечелиус О.Ю., Серга И Н., Чернякова Ю.Г.

\section{РЕЛЯТИВИСТСКАЯ ТЕОРИЯ СПЕКТРАЛЬНЫХ ХАРАКТЕРИСТИК ПИОН- НЫХ АТОМНЫХ СИСТЕМ: ПРИМЕНЕНИЕ К ТЯЖЕЛЫМ СИСТЕМАМ}

Резюме. Разработан новый теоретический подход к описанию энергетических и спектральных параметров адронных (пионных) атомов с аккуратным учетом релятивистских, радиационных и ядерных эффектов. Приведены данные расчета энергетических и спектральных параметров пионных атомов ${ }^{93} \mathrm{Nb},{ }^{173} \mathrm{Yb},{ }^{181} \mathrm{Ta},{ }^{197} \mathrm{Au}$ с учетом радиационных (поляризация вакуума), ядерных (конечный размер ядра) поправок и эффекта и сильного пион-ядерного взаимодействия. Для сравнения также приведены экспериментальные значения (измерения в лабораториях в Беркли, ЦЕРН и Вирджинии) и альтернативные теоретические данные, полученных в рамках других версий теории Клейна-Гордона-Фока с учетом конечного размера ядра в рамках модели однородно заряженной сферы и стандартного потенциалом Улинга-Сербера для учета радиационных поправок. .

Ключевые слова: релятивистская теория возмущений, энергетические параметры, пионные атомные системы. 
Дубровська Ю.В., Хещеліус О.Ю., Сєрга І.М., Чернякова Ю.Г.

\section{РЕЛАТИВІСТИЧНА ТЕОРІЯ СПЕКТРАЛЬНИХ ХАРАКТЕРИСТИК ПІОННИХ АТОМНИХ СИСТЕМ: ЗАСТОСУВАННЯ ДО ВАЖКИХ СИСТЕМ}

Резюме. Розроблено новий теоретичний підхід до опису енергетичних і спектральних параметрів адронних (піонних) атомів з акуратним урахуванням релятивістських, радіаційних і ядерних ефектів.. Наведены дані розрахунку енергетичних і спектральних параметрів піонних атомів ${ }^{93} \mathrm{Nb},{ }^{173} \mathrm{Yb},{ }^{181} \mathrm{Ta},{ }^{197} \mathrm{Au}$ з урахуванням радіаційних (поляризація вакууму), ядерних (кінцевий розмір ядра) поправок і ефекту сильного піонядерної взаємодії. Для порівняння також наведені експериментальні значення (вимірювання в лабораторіях в Берклі, ЦЕРН і Вірджинії) і альтернативні теоретичні дані, отримані в рамках інших версій теорії Клейна-Гордона-Фока з урахуванням кінцевого розміру ядра в рамках моделі однорідно зарядженої сфери і стандартним потенціалом Улінга-Сербера для урахування радіаційних поправок.

Ключові слова: релятивістська теорія збурень, енергетичні параметри, піонні атомні системи. 